九州大学学術情報リポジトリ

Kyushu University Institutional Repository

\title{
Effect of Repeated Exposure to Low 0xygen on Respiratory Metabolism and Vertical Movements in the Pen Shell Atrina Lischkeana
}

Honda, Masato

Laboratory of Marine Environmental Science, Faculty of Agriculture, Kyushu University

Gunjikake, Hiroaki

Laboratory of Marine Environmental Science, Faculty of Agriculture, Kyushu University

Matsui, Shigeaki

Fukuoka Fisheries and Marine Technology Research Center

Qiu, Xuchun

Laboratory of Marine Environmental Science, Faculty of Agriculture, Kyushu University

他

https://doi.org/10.5109/1854011

出版情報：九州大学大学院農学研究院紀要. 62 (2)，pp. 387-392，2017-09-08. Faculty of Agriculture, Kyushu University

バージョン :

権利関係 : 


\title{
Effect of Repeated Exposure to Low Oxygen on Respiratory Metabolism and Vertical Movements in the Pen Shell Atrina lischkeana
}

\author{
Masato HONDA ${ }^{1}$, Hiroaki GUNJIKAKE ${ }^{1}$, Shigeaki MATSUI ${ }^{2}$, Xuchun QIU' \\ Yohei SHIMASAKI ${ }^{2}$ and Yuji OSHIMA ${ }^{1, *}$
}

\author{
Laboratory of Marine Environmental Science, Faculty of Agriculture, Kyushu University, 6-10-1 Hakozaki, \\ Higashi-ku, Fukuoka 812-8581, Japan \\ (Received April 28, 2017 and accepted May 10, 2017)
}

\begin{abstract}
We exposed pen shells (Atrina lischkeana) to repeated periods of low-oxygen for $30 \mathrm{~d}$ and measured their survival, behavior, glycogen content, and organic acid concentration. Exposure to low-oxygen had no effect on survival. Animals moved upward above the sediment under low-oxygen conditions and downward under aerobic conditions, repeating these movements for $19 \mathrm{~d}$. The difference in shell height above the sediment before and after low-oxygen exposure gradually decreased; after $20 \mathrm{~d}$ there was no significant difference. Low-oxygen exposure also resulted in a significant decrease in glycogen content and in concentrations of malate and fumarate. Thus, repeated exposure of pen shells to low-oxygen conditions reduces glycogen content, alters metabolism, and affects vertical movements, all of which may cause ecological dysfunction. We suggest that hypoxia might be one factor contributing to the collapse of pen shell resources.
\end{abstract}

Key words: Repeated low-oxygen exposure, pen shell, glycogen, organic acid, up-and-down movement

\section{INTRODUCTION}

Recently, there has been an increase in the documented occurrence of hypoxic water masses $(<2 \mathrm{mg}$ $\mathrm{O}_{2} / \mathrm{L}$ ) in coastal areas around the world (Diaz and Rosenberg, 2008; Rabalais et al., 2010; Wu, 2002; Yanagi, 2004). In general, hypoxia develops as a result of natural upwelling (Grantham et al., 2004) or anthropogenic eutrophication (Barun et al., 1996; Kemp et al., 2005). Eutrophication induced hypoxia is a particularly serious problem, both for the environment (Middelburg and Levin, 2009) and for biogeocenoses (Levin et al., 2009), in many coastal areas. In the Ariake Sea, Japan, excessive consumption of dissolved oxygen by decomposing algae (red tides) can lead to hypoxia during the summer (Tanaka and Odagiri, 2010). The hypoxic water mass in the benthic region of the Ariake Sea is typically moved by tidal currents within a short duration, ranging from several hours to several days (Tokunaga et al., 2009; K. Sugino, Fukuoka Fisheries \& Marine Technology Research Center Ariakekai Laboratory, pers. Comm.). Therefore, it is expected to affect the benthic ecosystems (Yoshino et al., 2010). It is thought that repeated exposure to hypoxic water masses contributes to the observed decrease in the abundance of benthic bivalves in Japan (Hirano et al., 2010; Sato, 2006).

Pen shells Atrina lischkeana form the basis of an important fishery in Japan. However, the species has suffered a collapse after a mass mortality after 2000 in the Ariake Sea, Kyushu (Matsui, 2002). This collapse has been attributed to hypoxia (Matsui, 2002), deterioration

\footnotetext{
Laboratory of Marine Environmental Science, Faculty of Agriculture, Kyushu University, 6-10-1 Hakozaki, Higashi-ku, Fukuoka 812-8581, Japan

Fukuoka Fisheries and Marine Technology Research Center, 1141-1 Imazu, Nishi-ku, Fukuoka 819-0165, Japan

* Corresponding author: E-mail address: yoshima@agr. kyushu-u.ac.jp (Y. Oshima)
}

of sediment (Yurimoto et al., 2008), predation by rays (Kawahara et al., 2004), and increased sulfide levels (K. Sugino, Fukuoka Fisheries \& Marine Technology Research Center Ariakekai Laboratory, pers. comm.), though the exact cause remains unclear. The pen shells in the Ariake Sea are repeatedly exposed to hypoxic water transported by tidal currents (Tokunaga et al., 2009). We hypothesized that repeated exposure to hypoxia has contributed to the collapse of pen shell resources.

A number of studies have evaluated the effects of hypoxia on bivalves and have demonstrated a reduction in survival (Uzaki et al., 2003), deterioration of the physiological state (Sobral and Widdows, 1997), inhibition of larval settlement, and decreased juvenile growth and survival (Baker and Mann, 1992). Bivalves are known to have a well-developed and specific anaerobic respiratory system (Hochachka, 1980). Under normal aerobic conditions, bivalves can produce energy by glycogen breakdown through the glycolytic pathway, the tricarboxylic acid cycle (TCA cycle), and the electron transfer system. Aerobic metabolism yields water and $\mathrm{CO}_{2}$ as end products. However, under anaerobic conditions, bivalves can produce energy through the glycolytic pathway, using glycogen and aspartate as substrates and using backflow from part of the TCA cycle. Anaerobic metabolism generates succinate, propionate, and opines as end products. Bivalves produce 38 ATP by aerobic respiration and produce only 6 ATP by anaerobic respiration from one glycogen molecule (Hochachka, 1980). A decrease in glycogen content (Zwaan and Skjoldal, 1979) and changes in concentrations of certain organic acids (e.g., succinate) (Isani et al., 1995; Pörter et al., 1984) usually occur during anaerobic respiration hence, glycogen content and organic acid concentrations are indicative of the physiological state in bivalves and their response to hypoxia.

Exposure to hypoxia has a number of effects on the 
physiology of bivalves, including a reduction in respiration and growth (Cheung et al., 2008), accumulation of lactate (Zwaan et al., 1991), and a reduction in energy intake (Liu et al., 2011), however in most cases these studies were conducted under continuous low-oxygen conditions. Benthic organisms in the costal environment are often exposed to hypoxia periodically rather than continuously. Few studies have been performed on the effects of periodic exposure of bivalves to hypoxic conditions. Thus, little is known about the effects on metabolism and energy reserves. Gunjikake et al. (2009) reported a decrease in the survival of pen shells that were repeatedly exposed to low-oxygen conditions similar to those found in the environment. However, that study only evaluated the effect of repeated low-oxygen exposure on survival and movement in the pen shell. Our objective was to determine the effects of repeated low-oxygen exposure on survival, behavior, and physiology in pen shells. Our results provide insight into the mechanisms leading to the decline of pen shell populations in Japan.

\section{MATERIALS AND METHODS}

\section{Pen shell collection and maintenance}

Pen shells were collected from the Ariake Sea, off the shore of Oura, Kyushu, Japan, in July 2009. The pen shells (average shell length \pm SD: $136.6 \pm 7.2 \mathrm{~mm}$ ) were acclimatized in $3 \mathrm{~L}$ plastic aquaria (height $20 \mathrm{~cm} \times$ diameter $15 \mathrm{~cm}$ ) filled with sand to a depth of $13 \mathrm{~cm}$ under a flow of filtered seawater at a flow rate of about $1 \mathrm{~L} / \mathrm{min}$ for $16 \mathrm{~d}$. Pen shells were fed daily in the morning with a diet suspension "M-1" (Nosan Corporation, Yokohama, Japan) at $1 \%$ of soft body weight. Animals were maintained under natural light conditions.

\section{Repeated exposure of pen shells to low-oxygen}

The exposure group consisted of 15 replicates, each containing three pen shells in a plastic aquarium that was supplied with a continuous flow of filtered seawater. Water temperature ranged from 23.5 to $26.8^{\circ} \mathrm{C}$ during the exposure period. No food was provided during the experiment. During the $30 \mathrm{~d}$ exposure period, low-oxygen conditions $\left(<3.0 \mathrm{mg} \mathrm{O}_{2} / \mathrm{L}\right)$ were produced by bubbling the water with nitrogen gas on a daily basis as follows: at about $10 \mathrm{AM}$, the flow of seawater was stopped, the aquaria surfaces were covered with plastic sheets to prevent oxygen supply from air, and nitrogen gas was bubbled into the tank. After $6 \mathrm{~h}$ of low-oxygen condition, at about $4 \mathrm{PM}$, the plastic sheets were removed and the flow of air and seawater $(1 \mathrm{~L} / \mathrm{min}$ ) resumed. The control groups were set up in the same manner as the exposure group, except that the aquaria were supplied with aeration throughout the experiment ( $>6.5 \mathrm{mg} \mathrm{O}_{2} / \mathrm{L}$ ). The survival of the pen shells was checked daily, and individuals that failed to respond to a stimuli were considered dead and removed immediately.

Dissolved oxygen in each aquarium was monitored using a luminescent dissolved oxygen meter (HQ30d; Hach Company, Loveland, Colorado, USA) at $10 \mathrm{AM}$ and
4 PM daily. Coincident with the measurement of DO, the height of the shell extending above the sediment surface was measured (to the nearest $5 \mathrm{~mm}$ ) to indicate vertical movement. On day 0, 9, 20, and 30, six bivalves were randomly-selected and dissected, and their adductor muscles were sampled and stored at $-80^{\circ} \mathrm{C}$ until further analysis.

\section{Measurement of glycogen content}

The thawed adductor muscles were separated into subsamples that were used in subsequent analyses as follows: Glycogen content was measured using the anthrone method (Kamata and Hamada, 1985). Briefly, $1.5 \mathrm{~mL}$ of $30 \%$ potassium hydroxide solution was added to ca. $0.2 \mathrm{~g}$ of adductor muscle from a single individual and heated for $20 \mathrm{~min}$ in a boiling water bath. Then, $0.25 \mathrm{~mL}$ of saturated sodium sulfate solution and $2 \mathrm{~mL}$ of $95 \%$ ethanol were added and heated until boiling. The samples were centrifuged at 3,000 rpm for $5 \mathrm{~min}$ at $5^{\circ} \mathrm{C}$, and the pellets were resuspended in $5 \mathrm{~mL}$ of ultrapure water. Following this, $5 \mathrm{~mL}$ of anthrone reagent (13.5 M sulfuric acid, $12 \mathrm{mM}$ thiobromine, $4.7 \mathrm{mM}$ anthrone) was then added to $1 \mathrm{~mL}$ of the suspension, heated in the boiling water bath for $15 \mathrm{~min}$, and the absorbance was measured using a U-2001 spectrophotometer (Hitachi, Tokyo, Japan) at $620 \mathrm{~nm}$. Standard solutions (0, 0.125, 0.250, $0.500,1.000 \mathrm{mg} / \mathrm{mL}$ ) were used to obtain a standard curve. Glycogen content in the adductor muscle was calculated and reported as mg glycogen per g wet weight of adductor muscle.

\section{Measurement of organic acid concentration}

Concentrations of malate, pyruvate, lactate, succinate, fumarate, and propionate in the adductor muscle were measured using the method of Inoue et al. (2007). These organic acids are typical aerobic or anaerobic metabolites. Briefly, a subsample of the adductor muscle $(0.3 \mathrm{~g})$ was homogenized by eight times the amount by volume of $7 \%$ perchloric acid using a Polytron homogenizer (PT3100; Kinematica, Littau, Switzerland). The homogenate was centrifuged at 10,000 rpm for $30 \mathrm{~min}$ at $5^{\circ} \mathrm{C}$, then the supernatant was filtered through a $0.45 \mu \mathrm{m}$ filter (DISMIC-13HP; ADVANTEC, Tokyo, Japan). The different organic acids in the filtrate $(100 \mu \mathrm{L})$ were separated using high performance liquid chromatography (Waters 2690; Waters, Milford, MA, USA) and an Aminex HPX-87H organic acid analysis column (300 × $7.8 \mathrm{~mm}$; Bio-Rad Laboratories, Hercules, CA, USA) at a flow rate of $0.6 \mathrm{~mL} / \mathrm{min}$ and a pressure of about $4 \mathrm{MPa}$. Column temperature was set at $60^{\circ} \mathrm{C}$, and the mobile phase consisted of $8 \mathrm{mM}$ sulfuric acid. Organic acid content was detected by a UV detector system (Water 2487; Waters) at $210 \mathrm{~nm}$, and a mixed standard solution was used to obtain the standard curve.

\section{Statistical analyses}

Differences in survival between the control and exposure groups were evaluated using the generalized Wilcoxon test. Differences in glycogen content and organic acid concentrations were tested using the 
Mann-Whitney U test (R 2.9.1 software; Ihaka and Gentleman, 1996). Effect factor assessment on vertical movement data and glycogen content was performed using a two-way layout analysis of variance using SPSS 13.0 (SPSS, Inc., Chicago, IL, USA). In this analysis, lowoxygen exposure and time were set as the effect factors. The level of significance was $P<0.05$.

\section{RESULTS}

\section{Exposure to low oxygen and survival}

The average concentration of dissolved oxygen in the exposure group ranged from a low of $0.36 \pm$ $0.08 \mathrm{mg} \mathrm{O}_{2} / \mathrm{L}$ during the addition of nitrogen gas to 6.98 $\pm 0.08 \mathrm{mg} \mathrm{O}_{2} / \mathrm{L}$ during aeration with flowing seawater. The average in the control group was $6.92 \pm 0.18 \mathrm{mg} \mathrm{O}_{2} / \mathrm{L}$. There was no significant difference in survival between the control and exposure groups (Fig. 1).

\section{Movement of pen shells above the sediment sur- face}

Under low-oxygen conditions, the pen shells decreased the rate of shell opening/closing and gradually became indistinct for some tissues during the experimen-

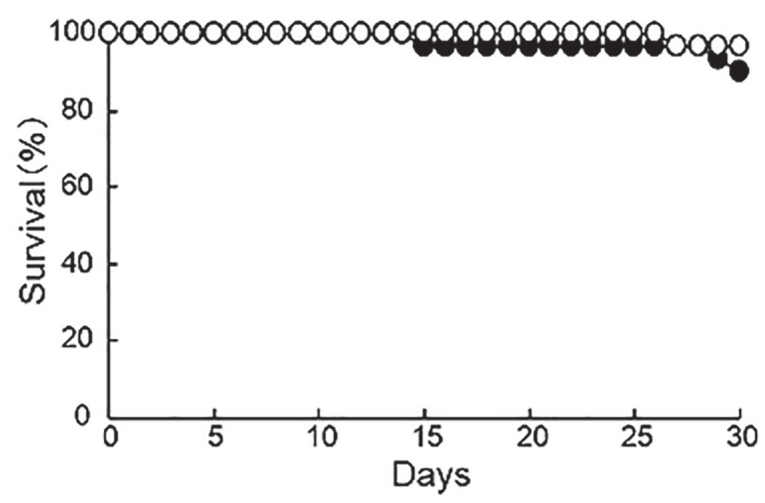

Fig. 1. Survival of pen shell that were repeatedly exposed to low-oxygen conditions for $6 \mathrm{~h} / \mathrm{d}(\mathbf{O})$ and the control (○) group.

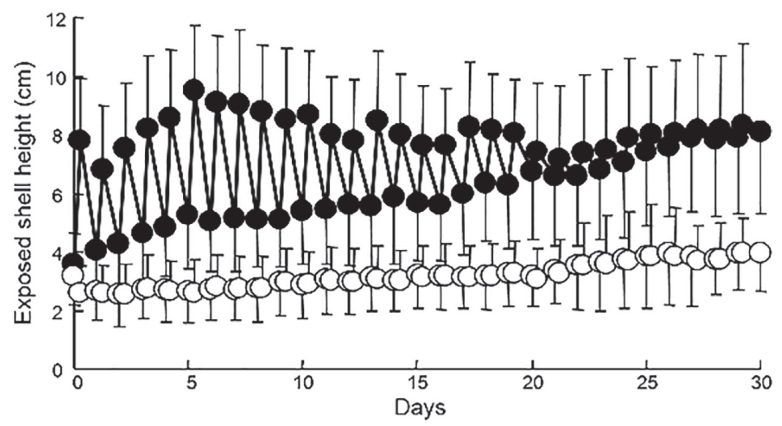

Fig. 2. Changes in the height of the pen shell measured from the sediment surface to the top of the shell during repeated ( $6 \mathrm{~h}$ during every $24 \mathrm{~h}$ period) low-oxygen exposure ( and the control group ( $\bigcirc)$. Each point represents the mean $\pm \mathrm{SD}$. tal period. The vertical movement of the pen shells is illustrated in Fig. 2. The pen shells migrated upward during the low-oxygen period then moved downward into the sand until they were almost buried during the aerobic period. These vertical movements of pen shells were repeated daily in association with exposure to low-oxygen conditions. The difference in pen shell heights above the sediment surface before and after low-oxygen exposure was significant between Day 0 and Day $19(P<0.01$; Wilcoxon rank sum test) in the exposure group. This difference gradually decreased thereafter, and was no longer detectable after $20 \mathrm{~d}$ of repeated low-oxygen exposure. At the end of the experiment, the entire shell was permanently exposed above the sediment. The height above the sediment was significantly different between the beginning and end of the experimental period in the exposure group. There was no significantdifference in pen shell heights before and after the $6 \mathrm{~h}$ period in the control group.

\section{Glycogen content}

There was a significant decrease in glycogen content in the adductor muscle of the exposure group relative to the control (Fig. 3; $P<0.05$ at both 9 days and 20 days). Both exposure and time had a significant effect on glycogen content (Two-way ANOVA $P<0.001, P<$ 0.05 respectively), but the interaction between time and exposure was not significant.

\section{Organic acid concentrations}

In general, succinate and propionate are metabolites of short and long term anaerobic respiration. Fig. 4 shows the organic acid concentrations in the adductor muscles of pen shells. There was a significant decrease in malate $(P<0.05$ at both 9 day and 30 day) and fumarate $(P<0.05$ at both 9 day and 30 day) levels in pen shells exposed to repeated low-oxygen conditions compared with control. The treatment had a significant effect on malate and fumarate levels (ANOVA, $P<0.05, P<$ 0.001 , respectively). The effect of time on organic acid

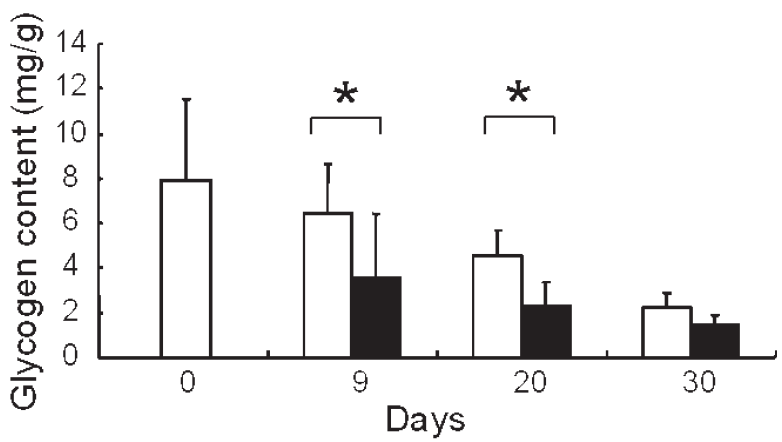

Fig. 3. Glycogen content in the adductor muscle of the pen shell repeatedly exposed ( $6 \mathrm{~h}$ during every $24 \mathrm{~h}$ period) to low-oxygen conditions ( $\square$ ) and in the control group (O). Each bar represents the mean \pm SD. * significantly different from control group (Mann-Whitney U test, $P<$ 0.05). 


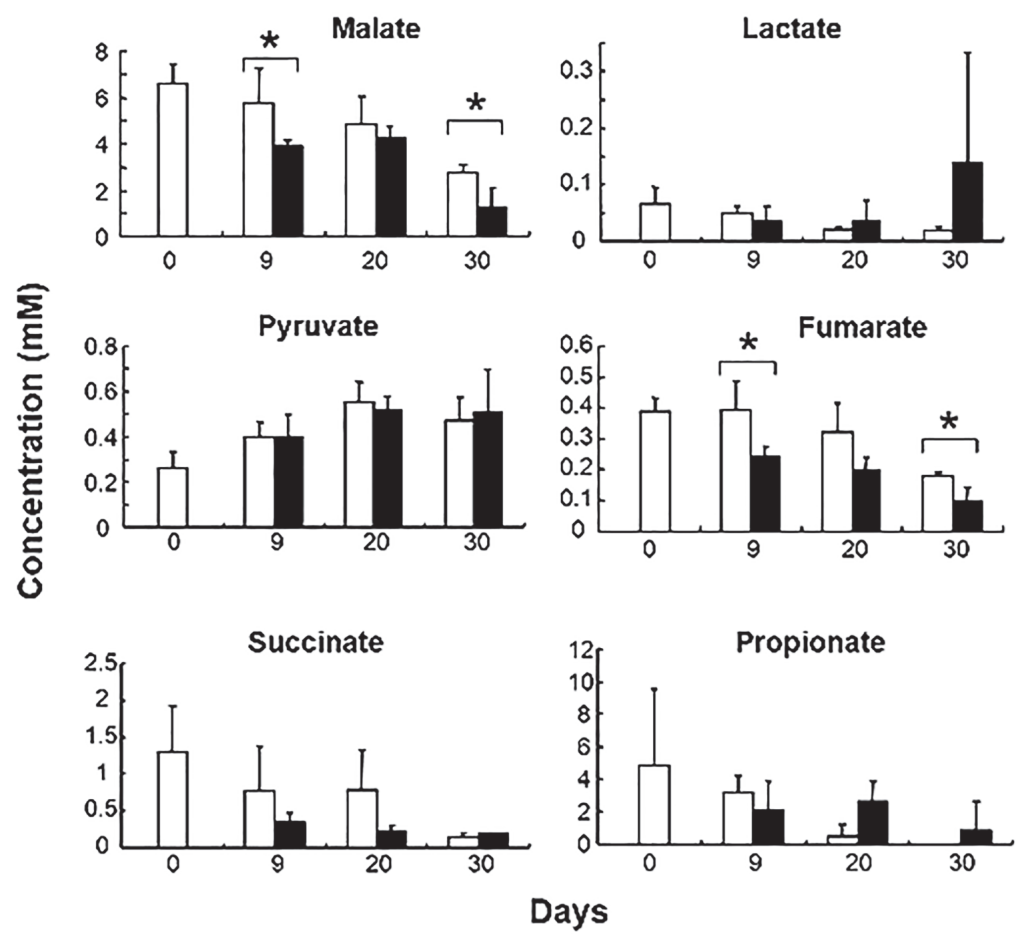

Fig. 4. Organic acid concentrations in the adductor muscle of the pen shell exposed to hypoxia $(\square)$ and in the control group $(\bigcirc)$. Each bar is a mean $\pm \mathrm{SD}$. * significantly different from control group (Mann-Whitney U test, $P<0.05$ ).

concentrations was significant for all organic acids tested, except lactate $(P<0.001$ for malate, pyruvate, succinate, fumarate, propionate).

\section{DISCUSSION}

In the natural environment, pen shells in the Ariake Sea are repeatedly exposed to hypoxic water masses as a result of the ebb and flood of tides (Tokunaga et al., 2009). The repeated exposure to low-oxygen in our study was intended to simulate this phenomenon. We observed pen shells moving upward under low-oxygen conditions and downward under aerobic conditions. This vertical movement was consistent each time animals were exposed to low-oxygen conditions, similar to our observations in a previous study (Gunjikake et al., 2009). Yamamoto et al. (2006) also observed upward movement of pen shells exposed to low-oxygen conditions (dissolved oxygen level $0.6 \mathrm{~mm} \mathrm{Hg}$ ) at $20^{\circ} \mathrm{C}$ for more than $30 \mathrm{~min}$, as did Matsui (2002) when pen shells were exposed to hypoxic benthic water in the Ariake Sea. Since biological demand for oxygen is high at the interface of the sediment and the overlying water body, oxygen concentrations above the sediment can be particularly low and diminish quickly. As such, the upward movement of pen shells during exposure to hypoxia may be regarded as an adaptive behavior to obtain more oxygen and to avoid this layer of hypoxic water. However, this behavior also results in an increase in energy expenditure.

Our results suggest there is a reduction in glycogen content in the adductor muscle of pen shells exposed to repeated low-oxygen conditions for 9-20 d. We attribute this reduction to the inefficiency of anaerobic respiration and to energy used for increased vertical movements. During aerobic respiration, bivalves produce 38 ATP from one glycogen molecule. However, under anaerobic respiration they produce only 6 ATP (Hochachka, 1980). A reduction in glycogen content due to continuous low-oxygen exposure for approximately 2-4 d has also been reported in Scapharca inaequivalvis (Isani et al., 1989) and in the freshwater bivalve Pleurobema coccineum (Badman and Chin, 1972). The decreasing glycogen content in the control group was likely associated with the lack of feeding during the experimental period. Regardless, the two-way layout analysis suggests that low-oxygen exposure significantly affects glycogen content, even after starving for $30 \mathrm{~d}$.

The vertical movement distance gradually decreased over time, and such movement ceased after $20 \mathrm{~d}$ exposure. This decrease likely reflects a general decrease in activity, reflected by the reduction in glycogen content (difference of shell height at before and after low-oxygen exposure versus glycogen content, spearman's rank correlation $P<0.05$ ). Taken together, our results suggest that repeated exposure to hypoxia causes an accelerated reduction in glycogen content as a result of anaerobic respiration and vertical movements.

We also observed a significant decrease in malate and fumarate levels following repeated exposure to low oxygen. This is consistent with prior observations in pen shells exposed to low-oxygen conditions (W. Tanoue, Faculty of Agriculture, Kyushu University, pers. comm.). We hypothesize that the decrease is due to the accumu- 
lation of anaerobic metabolites (e.g., succinate) induced by low-oxygen conditions. The recovery of malate and fumarate levels is likely not as rapid as that of anaerobic metabolites. Isani et al. (1989) noted an accumulation of succinate in the bivalve Scapharca inaequivalvis exposed to low oxygen, though levels returned to normal within $4 \mathrm{~h}$ after return to aerobic conditions. We did not detect the accumulation of succinate, lactate, or propionate in exposed pen shells. This may be because specimens were sampled about $18 \mathrm{~h}$ after their return to aerobic conditions, at which time they may have had already recovered from the effects of anaerobic respiration.

Exposure of pen shells to low-oxygen conditions for $6 \mathrm{~h}$ every day for $30 \mathrm{~d}\left(0.36 \pm 0.08 \mathrm{mg} \mathrm{O}_{2} / \mathrm{L}, 23.5-26.8^{\circ} \mathrm{C}\right)$ did not affect survival. In contrast, Gunjikake et al. (2009) recorded a significant increase in mortality of pen shells exposed daily $(6 \mathrm{~h})$ to low-oxygen conditions for $31 \mathrm{~d}\left(0.36 \pm 0.03 \mathrm{mg} \mathrm{O}_{2} / \mathrm{L}, 24.7-30.0^{\circ} \mathrm{C}\right)$. This difference in survival rate may reflect the slightly higher water temperatures in the earlier study. Akimoto et al. (2004) reported 50\% mortality in pen shells continuously exposed to low-oxygen conditions for $72 \mathrm{~h}$ at $27.5^{\circ} \mathrm{C}$ (dissolved oxygen level 14.9\%). In general, temperature decreases oxygen solubility and is associated with a concurrent increase in metabolic rate and energy expenditure in the bivalve (Ansell and Sivadas, 1973). Furthermore, under low-oxygen conditions, bivalves begin anaerobic respiration, which has low energy production (ATP) efficiency compared with aerobic respiration. It appears that exposure of pen shells to low-oxygen conditions for a long time or exposure to repeated low-oxygen conditions at high temperatures results in energy exhaustion and hence mass mortality.

Since the beginning of this century, a dramatic collapse of pen shell resources has occurred in Ariake Sea. Matsui (2002) documented the mass mortality of pen shells after they moved upward in the sediment under hypoxic water conditions during the summer. Our study suggests that periodic exposure to hypoxic water results in anaerobic metabolism and a subsequent reduction in glycogen content. Repeated exposure of pen shells to hypoxic water initially causes repeated upward and downward movements in the sediment. However, after several days the animals no longer exhibiting burrowing behavior, instead remaining above the sediment surface. Long et al. (2008) reported that exposure of the bivalve Macoma balthica to low-oxygen conditions $(<2.5 \mathrm{mg}$ $\mathrm{O}_{2} / \mathrm{L}$ ) for $72 \mathrm{~h}$ reduced their burial depths and increased their vulnerability to predators. Our results suggest that hypoxia is likely to be a major cause of mass mortality of pen shells, possibly in conjunction with other environmental factors. This is consistent with Matsui (2002), who concluded that the decrease in pen shell abundance was due to exposure to hypoxic conditions and high temperatures in the summer, and other factors, such as becoming weak following reproduction.

In conclusion, repeated exposure of pen shells to low-oxygen conditions reduces glycogen content and initially induces upward and downward movements. After several days of exposure, the animals remained above the sediment so were perhaps vulnerable to predators. Our results may help to explain the collapse of pen shell resources. Further studies should be carried out to investigate the combined effect of exposure to hypoxia and high temperatures. In addition, little is known about the effects of predation, or of sulfide and ammonia toxicity associated with hypoxia.

\section{AUTHOR CONTRIBUTION}

M. Honda designed the study, performed the whole experiments, analyzed data and wrote the paper. $\mathrm{H}$. Gunjikake participated in the design of study and whole experiment. S. Matsui participated in the design of study and provided facilities and resources. X. Qiu and Y. Shimasaki participated in the design of study and edited the paper. Y. Oshima designed the study, supervised the work, wrote the paper and provided facilities and resources. All authors assisted in editing of the manuscript and approved the final version.

\section{ACKNOWLEDGEMENTS}

This work was supported in part by a grant from the Ministry of Education, Culture, Sports, Science, and Technology of Japan (17310027). Many thanks to staff at the Fukuoka Fisheries and Marine Technology Research Center.

\section{REFERENCES}

Akimoto, T., M. Hayashi, M. Iwabuchi and K. Yamamoto 2004 Lethal oxygen-saturation for the pen shell Atrina (Servatrina) lischkeana. Aquacult. Sci., 52: 199-200 (in Japanese)

Ansell, A. D. and P. Sivadas 1973 Some effects of temperature and starvation on the bivalve Donax vittatus (da Costa) in experimental laboratory populations. J. Exp. Mar. Biol. Ecol., 13: $229-262$

Badman, D. G. and S. L. Chin 1972 Metabolic responses of the fresh-water bivalve, pleurobema coccineum (Conrad), to anaerobic conditions. Comp. Biochem. Phys. B., 44: 27-32

Baker, S. M. and R. Mann 1992 Effects of hypoxia and anoxia on larval settlement, juvenile growth, and juvenile survival of the oyster Crassostrea virginica. Biol. Bull., 182: 265-269

Barun, K., S. Gupta, R. E. Turner and N. N. Rabalais 1996 Seasonal oxygen depletion in continental-shelf waters of Louisiana: Historical record of benthic foraminifers. Geology, 24: $227-230$

Cheung, S. G., H. Y. Chan, C. C. Liu and P. K. S. Shin 2008 Effect of prolonged hypoxia on food consumption, respiration, growth and reproduction in marine scavenging gastropod Nassarius festivus. Mar. Pollut. Bull., 57: 280-286

Diaz, R. J. and R. Rosenberg 2008 Spreading dead zones and consequences for marine ecosystems. Science, 321: 926-929

Grantham, B. A., F. Chan, K. J. Nielsen, D. S. Fox, J. A. Barth, A. Huyer, J. Lubchenco and B. A. Menge 2004 Upwelling-driven nearshore hypoxia signals ecosystem and oceanographic changes in the northeast Pacific. Nature, 429: 749-754

Gunjikake, H., Y. Ohshima, S. Matsui, W. Tanoue, K. Imanishi, M. Honda, J. Moroishi, I. J. Kang, Y. Shimasaki and T. Honjo 2009 Effects of hypoxia on behavior and mortality of pen shell (Atrina lischkeana). Sci. Bull. Fac. Agr. Kyushu univ., 64 19-22 (in Japanese)

Hirano, K., J. Higano, H. Nakata, A. Shinagawa, T. Fujita, M. Tokuoka, and K. Kogo 2010 An experiment for preventing massmor- 
tality of cultured short-neck clams due to hypoxia formation during summer in Isahaya Bay. Jpn. Soc. Fish Eng., 47: 53-62 (in Japanese)

Hochachka, P. W. 1980 Living without oxygen: closed and open systems in hypoxia tolerance. Harvard University Press, Cambridge (USA), pp. 1-181

Ihaka, R. and R. Gentleman 1996 R: A language for data analysis and graphics. J. Comp. Graph. Stat., 5: 299-314

Inoue, S., Y. Oshima, S. Abe, R. S. S. Wu, N. Kai and T. Honjo 2007 Effects of tributyltin on the energy metabolism of pen shell (Atrina pectinata japonica). Chemosphere, 66: 1226-1229

Isani, G., O. Cattani, E. Carpene, S. Tacconi and P. Cortesi 1989 Energy metabolism during anaerobiosis and recovery in the posterior adductor muscle of the bivalve Scapharca inaequivalvis (Bruguiere). Comp. Biochem. Physiol., 93: 193-200

Isani, G., O. Cattani, M. Zurzolo, C. Pagnucco and P. Cortesi 1995 Energy metabolism of the mussel, Mytilus galloprovincialis, during long-term anoxia. Comp. Biochem. Physiol., 110: 103-113

Kamata, H. and T. Hamada 1985 Comparison of anthrone and enzymatic methods for hepatic glycogen analyses. Bull. Nat. Inst. Anim. Ind., 43: 85-92 (in Japanese)

Kawahara, I., S. Ito and A. Yamaguchi 2004 Influence of the bullnose ray, aetobatus flagellum, on the pen-shell, Atrina pectinata, in Ariake Sound. In "Bull of Saga Prefectural Ariake Fisheries Research and Development Cent", Vol. 22, Saga Prefectural Ariake Fisheries Experimental Station, Saga, pp. 29-33 (in Japanese)

Kemp, W. M., W. R. Boynton, J. E. Adolf, D. F. Boesch, W. C. Boicourt, G. Brush, J. C. Cornwell, T. R. Fisher, P. M. Glibert, J. D. Hagy, L. W. Harding, E. D. Houde, D. G. Kimmel, W. D. Miller, R. I. E. Newell, M. R. Roman, E. M. Smith and J. C. Stevenson 2005 Eutrophication of Chesapeake Bay: historical trends and ecological interactions. Mar. Ecol.-Prog. Ser., 303: $1-29$

Levin, L. A., W. Ekau, A. J. Gooday, F. Jorissen, J. J. Middelburg, S. W. A. Naqvi, C. Neira, N. N. Rabalais and J. Zhang 2009 Effects of natural and human-induced hypoxia on coastal benthos. Biogeosciences, 6: 2063-2098

Long, W. C., B. J. Brylawski and R. D. Seitz 2008 Behavioral effects of low dissolved oxygen on the bivalve Macoma balthica. J. Exp. Mar. Biol. Ecol., 359: 34-39

Matsui, S. 2002 Resources change of the pen-shell (Atrina pectinata japonica) in northeast part fishery of Ariake Sea. In "Bull Fukuoka Fish Mar Technol Res Cent", Vol. 12, Fukuoka Fisheries and Marine Technology Research Center, Fukuoka, pp. 29-35 (in Japanese)

Middelburg, J. J. and L. A. Levin 2009 Coastal hypoxia and sediment biogeochemistry. Biogeosciences, 6: 1273-1293

Pörter, H. O., M. K. Grieshaber and N. Heisler 1984 Anaerobiosis and acid-base status in marine invertebrates: effect of environmental hypoxia on extracellular and intracellular $\mathrm{pH}$ in Sipunculus nudus L. J. Comp. Physiol. B, 155: 13-20

Rabalais, N. N., R. J. Diaz, L. A. Levin, R. E. Turner, D. Gilbert and J. Zhang 2010 Dynamics and distribution of natural and human-caused hypoxia. Biogeosciences, 7: 585-619

Sato, S. 2006 Drastic change of bivalves and gastropods caused by the huge reclamation projects in Japan and Korea. Plankton Benthos Res., 1: 123-137

Sobral, P. and J. Widdows 1997 Influence of hypoxia and anoxia on the physiological responses of the clam Ruditapes decussatus from southern Portugal. Mar. Biol., 127: 455-461

Tanaka, M. and M. Odagiri 2010 Mechanism of the oxygendepleted water formation near the head of the Ariake Bay and its numerical modeling. Journal of JSCE, Ser B2 (Coastal Engineering), 66: 1011-1015 (in Japanese)

Tokunaga, T., M. Kodama, K. Kimoto and Y. Shibahara 2009 Characteristics of hypoxia in the inner western area of Ariake Bay. Journal of JSCE, Ser B2 (Coastal Engineering), 65: 1011-1015 (in Japanese)

Uzaki, N., M. Kai, H. Aoyama and T. Suzuki 2003 Changes in mortality rate and glycogen content of the manila clam Ruditapes philippinarum during the development of oxygen-deficient waters. Fisheries Sci., 69: 936-943

Wu, R. S. S. 2002 Hypoxia: from molecular responses to ecosystem responses. Mar. Pollut. Bull., 45: 35-45

Yamamoto, K., T. Handa and A. Nishioka 2006 Effect of hypoxia on ventilation in the pen shell Atrina (Servatrina) lischkeana. Aquac. Sci., 54: 319-323 (in Japanese)

Yanagi, T. 2004 Hypoxia: the chemical and biological consequences of the mechanisms of its generation, maintenance, variability and disappearance. Oceanogra. Jpa., 13: 451-460 (in Japanese)

Yoshino, K., T. Hamada, K. Yamamoto, Y. Hayami, S. Yamaguchi and K. Ohgushi 2010 Effects of hypoxia and organic enrichment on estuarine macrofauna in the inner part of Ariake Bay. Hydrobiologia, 652: 23-38

Yurimoto, T., K. Tanaka, H. Nasu and K. Matsuoka 2008 Influence of resuspended sediments and their surface accumulation on a pen shell Atrina pectinata in Ariake Bay, west Japan. Aquacul. Sci., 56: 335-342 (in Japanese)

Zwaan, A. D., P. Cortesi, G. V. D. Thillart, J. Roos and K. B. Storey 1991 Differential sensitivities to hypoxia by two anoxia-tolerant marine molluscs: A biochemical analysis. Mar. Biol., 111 343-351

Zwaan, A. D. and H. R. Skjoldal 1979 Anaerobic energy metabolism of the scavenging lsopod Cirolana borealis (Lilljeborg). $J$. Comp. Physiol. B., 129: 327-331 